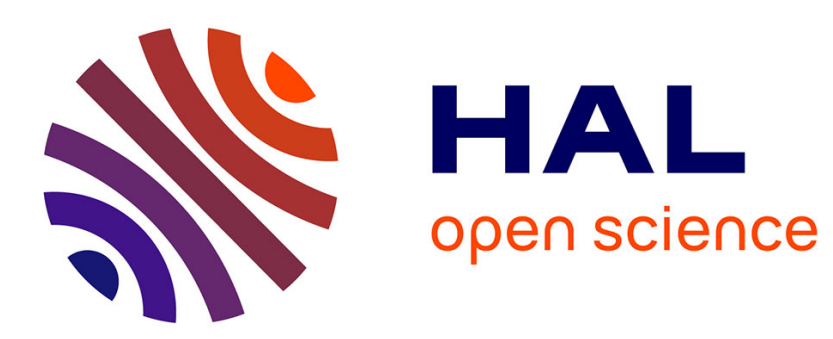

\title{
Effect of temperature on the high strain-rate fracture characteristics of ductile metals
}

\author{
D. Barton, M. Mirza, J. Sturges, M. Waheed
}

\section{To cite this version:}

D. Barton, M. Mirza, J. Sturges, M. Waheed. Effect of temperature on the high strain-rate fracture characteristics of ductile metals. Journal de Physique IV Proceedings, 1994, 04 (C8), pp.C8-659-C8664. 10.1051/jp4:19948100 . jpa-00253341

\section{HAL Id: jpa-00253341 https://hal.science/jpa-00253341}

Submitted on 1 Jan 1994

HAL is a multi-disciplinary open access archive for the deposit and dissemination of scientific research documents, whether they are published or not. The documents may come from teaching and research institutions in France or abroad, or from public or private research centers.
L'archive ouverte pluridisciplinaire HAL, est destinée au dépôt et à la diffusion de documents scientifiques de niveau recherche, publiés ou non, émanant des établissements d'enseignement et de recherche français ou étrangers, des laboratoires publics ou privés. 


\title{
Effect of temperature on the high strain-rate fracture characteristics of ductile metals
}

\author{
D.C. Barton, M.S. Mirza, J.L. Sturges* and M. Waheed \\ Department of Mechanical Engineering, University of Leeds, Leeds LS2 9JT, U.K. \\ *Department of Construction Engineering, Metropolitan University of Leeds, Leeds LSI 3ME, U.K.
}

\begin{abstract}
Résumé: Un chauffage par induction a été employé pour éléver rapidement la température d'une éprouvette en acier et d'une óprouvette en fer pur, avant de les tester au vitesses de déformation > $10^{3} \mathrm{~s}^{-1}$. Les résultats montrent en général que la ductibilité diminue pour des températures au-delà des limites testées $\left(20-400^{\circ} \mathrm{C}\right)$. Basé sur des informations expérimentales et sur les résultats de simulations numérique de l'essai, un modéle empirique a été derivé pour du fer pur et donne la tension de fracture en fonction des contraintes et de la température. Récemment, la technique de chauffage par induction a été étendue aux materiaux non-ferreux. Des tests à fortes tension sur du cuivre à 99,99\% pur n'ont pas révélé les effets de la température sur la ductibilité du materiaux audessus des températures employées $\left(20-300^{\circ} \mathrm{C}\right)$.
\end{abstract}

\begin{abstract}
Induction heating has been employed to rapidly raise the temperature of ferrous specimens prior to testing at strain-rates $>10^{3} \mathrm{~s}^{-1}$. The results show a general tendency for the ductility of a specially-processed pure iron to decrease with temperature over the range tested (20$400 \mathrm{C}$ ). Based on the experimental data and the results of numerical simulations of the experiment, an empirical fracture model has been derived for the iron which gives fracture strain as a function of state-of-stress and temperature. Recently, the induction heating technique has been extended to nonferrous materials. High strain-rate tests on $99.9 \%$ pure copper revealed no significant effect of temperature on ductility over the range of start temperatures employed $(20-300 \mathrm{C})$.
\end{abstract}

\section{INTRODUCTION}

A feature of high strain-rate testing of materials is the adiabatic temperature rise which inevitably accompanies the rapid plastic work. This temperature rise can make the interpretation of nominally isothermal test results difficult since temperature is known to significantly affect certain properties such as the material flow stress. This problem may be particularly acute when one is attempting to determine high strain-rate fracture characteristics since the adiabatic temperature rise for ductile materials at the estimated site and time of fracture initiation is often substantial. It is therefore desirable to determine the sensitivity of the ductile fracture process to temperature so that adjustments to any experimentally-derived fracture models can be made accordingly.

The present paper describes a technique based on the induction heating process to rapidly heat metallic specimens prior to high strain-rate testing in order to vary the temperature at fracture and thereby study the effect of this parameter on ductility. Induction heating of the specimen was chosen because it is noncontacting and should be sufficiently rapid to prevent any microstructure changes occurring in the material over the short total time at elevated temperature. The first section below describes the basis of this technique and how it has been applied to heat specimens held in the particular high strain-rate rig used at Leeds (the 
'flying wedge'). The next section describes tests carried out on plain (unnotched) mild steel specimen and pre-notched specially-processed pure iron ( known as AQ85 iron) over a range of temperatures. In the case of the latter material, derivation of an empirical fracture model based on the test data and results from numerical simulations of the experiment (which includes calculation of the adiabatic temperature rise) is described. The application of the induction heating technique to non-ferrous specimen is then detailed followed by presentation of the results of tests on high-purity copper over a range of temperatures. Finally, conclusions are drawn and the wider implications of the results discussed.

\section{INDUCTION HEATING TECHNIQUE}

Induction heating is a method of quickly heating metals by inducing current through them from a separate source. It is based on three main principles: electromagnetic induction, the skin effect and heat transfer. Electromagnetic heating is the basis of all induction heating [1]. The basic concept is similar to the wellknown transformer theory but modified and based on a single-turn, short-circuited secondary winding. The passage of an alternating current in a primary circuit produces a magnetic field which induces an alternating current in any neighbouring magnetic metal. Due to the 'skin effect' phenomenon when a rapid alternating current flows in a metallic workpiece, a highly selective heating source is created in the metal. In a typical assembly the metal to be heated is placed within an induction coil. The alternating current in the coil establishes the required alternating magnetic flux around the workpiece.

In the present work, a radio frequency induction heater operating at $5 \mathrm{NMHz}$ with a maximum output power capacity of $1.5 \mathrm{~kW}$ (manufacturer: Radyne Ltd.) has been used to heat specimens. Tests at different elevated temperatures and at high strain-rates were performed on the dynamic tensile testing apparatus known as the 'ffying wedge' which is capable of producing strain-rates in excess of $10^{4} \mathrm{~s}^{-1}$ [3]. A schernatic diagram of this rig is shown in Figure 1 from which the principle of operation should be obvious. Because of the space limitations imposed by the apparatus, an in-situ helical induction coil could not be used without fouling the wedge itself during test. Hence a U-shaped coil was constructed from high conductivity copper tubing which would be positioned around the specimen during the heating process but removed quickly prior to the test (Figure 2).

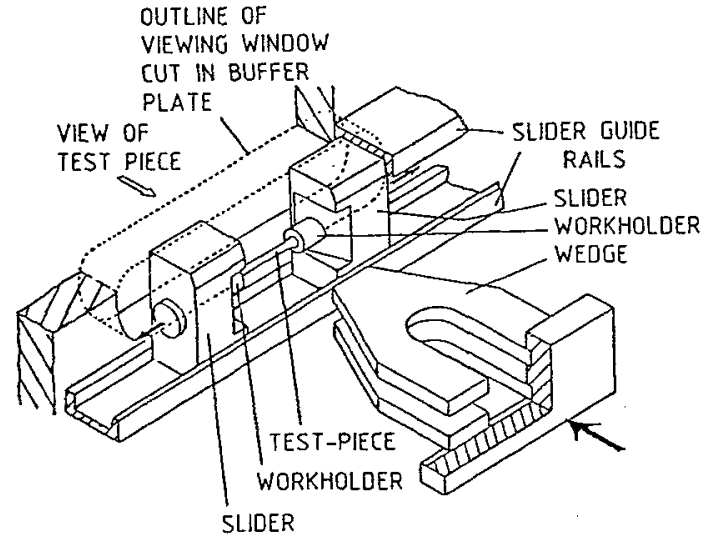

Figure 1: Flying Wedge tensile testing machine.

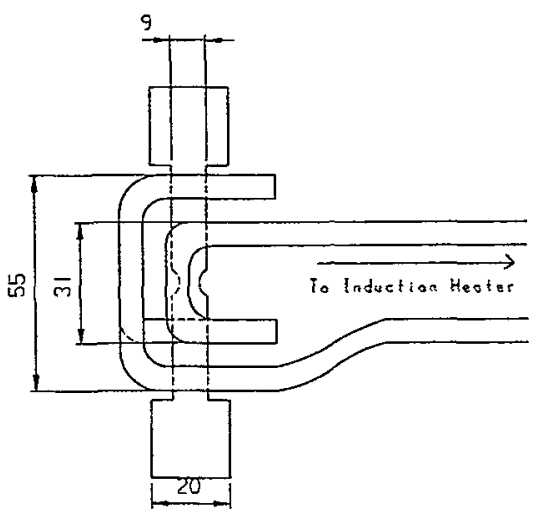

Figure 2: Induction heating coil and specimen.

\section{ELEVATED TEMPERATURE TESTS ON FERROUS METALS}

\subsection{Preliminary Trials}

Using a special mild steel specimen of dimensions shown in Figure $3 \mathrm{a}$ and with thermocouples attached at various locations, the temperature rise with the above coil was found to be more than adequately fast, a temperature of $650 \mathrm{C}$ being measured by an embediled thermocouple at the centre of the specimen after only 40 seconds of heating. The uniformity of tempcrature also turned out to be satisfactory with at most a. 
$15 \mathrm{C}$ temperature difference recorded by the centre and surface thermocouples at the end of the $10 \mathrm{~s}$ cooling period required to remove the coil and set up the wedge for firing. In order to verify that the microstructure of the specimen was not affected by this heating, the grain structure of mild steel specimens heated rapidly to different temperatures and then immediately allowed to cool was examined. No apparent change in the microstructure was found even at very high temperatures of upto $750 \mathrm{C}$.

Since embedded thermocouples cannot be attached to the actual specimens to be tested, the system has to be carefully calibrated for both heating time and the subsequent cooling time to reach a given target temperature using an instrumented specimen for each particular specimen size and material tested.

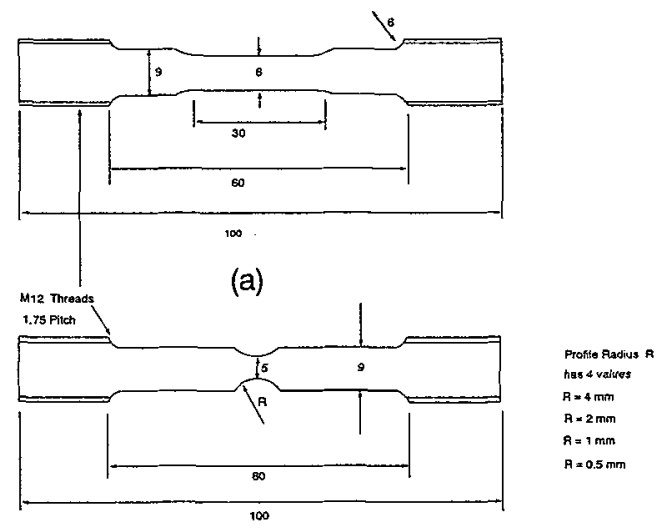

(b)

Figure 3: Specimen dimensions (a) Plain specimen (b) M12-pre notched specimen.

\subsection{Tests on Mild Steel}

Dynamic tensile tests on commercially available mild steel were carried out at test temperatures of 20,200 , 400 and $600 \mathrm{C}$ to investigate the effect of temperature on the ductility of this material at high strain-rate as well as to validate the new elevated temperature test technique. The dimensions of the plain(unnoticed) specimens used were as in Figure 3a. The results in terms of average effective plastic strain at fracture (defined as $2 \ln \left(d_{0} / d_{f}\right)$, where $d_{0}$ and $d_{f}$ are the initial and post fracture minimum diameters ) are plotted against test start temperature in Figure 4. It can be seen that the ductility at a test start temperature of $200 \mathrm{C}$ appears to be somewhat greater than at $20 \mathrm{C}$ but thereafter there is tendency for failure strains to fall with temperature. This is in general agreement with the results of Work \& Dolan [5] and is consistent with the onset of a dynamic ageing effect at about $200 \mathrm{C}$ at high strain-rate [4] for a similar material. One would expect the ductility to eventually start to increase as the temperature is raised further towards the melting point but this could not be investigated since $600 \mathrm{C}$ is the highest practical test start temperature achievable with the current heater unit.

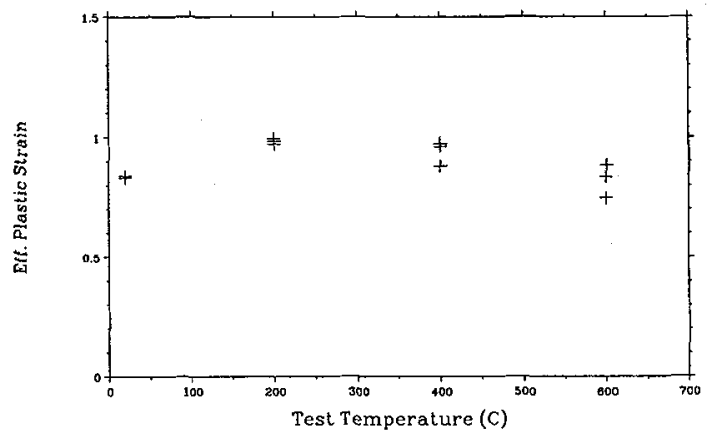

Figure 4: Failure strain versus test start temperature for mild steel. 


\subsection{Tests on AQ85 pure iron}

Previous tests starting at ambient temperature had shown the ductility of this material to be strongly dependent on stress triaxiality (defined as the ratio $\sigma_{m} / \sigma_{e}$ where $\sigma_{m}$ is the mean stress and $\sigma_{e}$ the von Mises effective stress) but only weakly affected by strain-rate. In order to investigate the effects of temperature in a controlled manner, tests at temperatures of 20,200 and $400 \mathrm{C}$ were carried out at a constant strain-rate of about $5 \times 10^{3} \mathrm{~s}^{-1}$. Pre-notched tensile specimens with notch profile radii of $4,2,1$ and $0.5 \mathrm{~mm}$ as shown in Figure $3 \mathrm{~b}$ were used to achieve different levels of stress triaxiality.

In order to properly interpret the experimental results, numerical simulations were carried out using the DYNA2D wave propagation finite element code for the three different start temperatures and the measured experimental loading conditions. The Zerilli-Armstrong constitutive relation [6], which accounts for the effect of temperature as well as strain-rate, was used for the material flow stress. Figure 5 shows the maximum local strains at failure (defined as the maximum effective strain predicted by DYNA2D when the reduction of radius in the simulation equals that measured after fracture of the actual specimen) versus $\sigma_{m} / \sigma_{e}$ at the same location for the different notch profles tested at 20,200 and $400 \mathrm{C}$. It can be seen that there is a clear tendency for the ductility at a given $\sigma_{m} / \sigma_{e}$ to decrease as start temperature is raised.

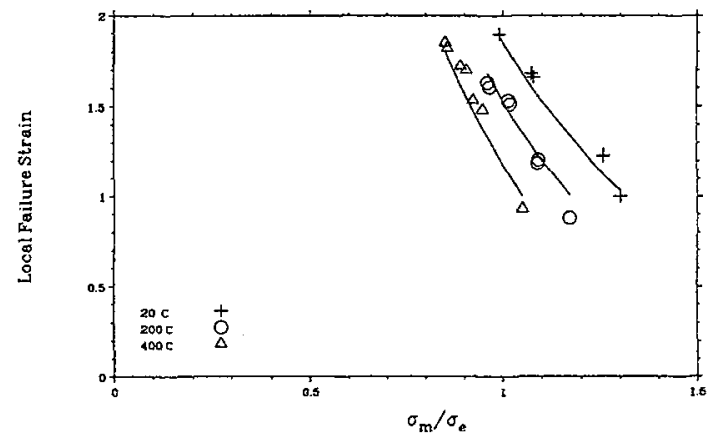

Figure 5: Local failure strain versus stress triaxiality factor for AQ85 pure iron.

From the experimental results for Figure 5, an empirical fracture model which is based on the work of Hancock and Mackenzie [2] but also takes account of the different test temperatures was derived:

$$
\epsilon_{f}=D_{1} \exp \left(-D_{2} \frac{\sigma_{m}}{\sigma_{e}}\right)+D_{3} T^{*}
$$

where $\epsilon_{f}$ is the effective failure strain and $T^{*}$ is the homologous temperat ure defined as $T^{*}=\frac{T_{o}-T_{r}}{T_{m}-T_{r}}$ where $T_{o}$ is the test start temperature, $T_{r}$ is the reference temperature $(20 \mathrm{C})$ and $T_{m}$ is the melting temperature. By fitting curves to the data shown in Figure 5, optimum values of the constants were found to be: $D_{1}=13.0$, $D_{2}=1.95, D_{3}=-2.7$.

The numerical simulations were repeated for each start temperature using Equation 1 together with the standard strain accumulation failure criterion in DYNA2D. This states that fracture occurs in a cell when an accumulated damage parameter defined as the ratio of plastic strain increment to the current fracture strain

$$
D_{j}=\Sigma \frac{\Delta \epsilon_{p}}{\epsilon_{f}}
$$

reaches a value of unity. The predicted fracture times and average effective strains at fracture are compared with experimentally measured values in Table 1 . Reasonable agreement between numerical prediction and experiment is obtained although the predicted fracture times and strains are generally both less than the measured values. This may be because predicted values are taken to be those when the first element fails according to the strain accumulation criterion and not when complete separation of the specimen occurs.

\section{ELEVATED TEMPERATURE TESTS ON COPPER}

Since induction heating works on the electromagnetic principle, its use with non-ferrous magnetic materials (e.g. copper, aluminium) results in a drastic reduction in efficiency for a given induction coil and heater 


\begin{tabular}{|c|c|c|c|c|c|}
\hline \multirow[t]{2}{*}{$\begin{array}{c}\text { Temperature } \\
\text { (C) }\end{array}$} & \multirow[t]{2}{*}{$\begin{array}{l}\text { Notch Radius } \\
\text { (mm) }\end{array}$} & \multicolumn{2}{|c|}{$\begin{array}{l}\text { Fracture Times } \\
(\mu \mathrm{s})\end{array}$} & \multicolumn{2}{|c|}{$\begin{array}{c}\text { Fracture strains } \\
-\end{array}$} \\
\hline & & experiment & numerical & experiment & numerical \\
\hline \multirow{4}{*}{20} & 4 & 256 & 216 & 1.94 & 2.14 \\
\hline & 2 & 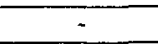 & 175 & - & 1.56 \\
\hline & 1 & $\overline{173}$ & 141 & 1.513 & 1.21 \\
\hline & 0.5 & 152 & 130 & 1.51 & 0.99 \\
\hline \multirow{4}{*}{200} & 4 & 231 & 251 & 1.78 & 2.60 \\
\hline & 2 & 218 & 203 & 1.85 & 1.83 \\
\hline & 1 & 210 & 170 & 1.65 & 1.32 \\
\hline & 0.5 & 206 & 150 & 1.39 & 0.93 \\
\hline \multirow{4}{*}{400} & $\overline{4}$ & 300 & 274 & 2.14 & 2.62 \\
\hline & 2 & 260 & 225 & 2.18 & 1.83 \\
\hline & 1 & 226 & 184 & 2.10 & 1.16 \\
\hline & $\overline{0.5}$ & 222 & 145 & 1.41 & 0.59 \\
\hline
\end{tabular}

Table 1: Comparison of experimental and numerical predictions of fracture times and strains for AQ85 at different test temperatures.

compared with ferrous metals. Therefore in order to heat non-ferrous metals directly by induction heating a high power generator is usually required. An alternative method could be to use induction heating in conjunction with conduction by fitting an iron sleeve around the non-ferrous specimen. The temperature of the iron sleeve would be raised by the induction heating process causing the heat to be conducted to the specimen. Since non-ferrous metals such as copper and aluminium have high thermal conductivities and the specimen size is small, specimens might be heated in reasonably quick times.

This technique has been used in the present work to test pure copper at elevated temperatures and high strain-rates. Using the same induction coil as before together with a close fitting iron sleeve of 3 $\mathrm{mm}$ thickness clamped around the specimen, it was found possible to raise the temperature at the centre of the specimen to $300 \mathrm{C}$ in about 50 seconds. A special remote clamping arrangement was developed to enable the sleeve to be removed from the heated specimen prior to testing. This allowed the normal current-interruption method of determining the fracture time to be used. Again, careful calibration tests were carried out on a copper specimen instrumented with thermocouples to determine suitable heating and cooling times to obtain the required target temperature at the moment of firing the wedge.

Pre-notched copper specimens with the geometry shown in Figure $3 \mathrm{~b}$ were tested at start temperatures of 20,150 and $300 \mathrm{C}$. Again, DYNA2D simulations were carried out using a Zerilli-Armstrong type relation for copper in order to correctly interpret the results which are shown according to test start temperature in Figure 6. The expected strong dependence of failure strain on the stress triaxiality parameter $\sigma_{m} / \sigma_{e}$ is obvious. However no clear trend with respect to start temperature can be discerned as was found for AQ85 pure iron (Figure 5). Therefore it seems reasonable to conclude that the fracture behaviour of copper is relatively temperature-independent over the range of conditions tested (previous tests had shown the ductility of copper to be also insensitive to strain-rate [3]). An isothermal version of equation (1) with $D_{3}=0$ was therefore fitted to the experimental points giving $D_{1}=12.7, D_{2}=2.48$ as optimised constants.

\section{CONCLUSIONS}

Induction heating has been successfully used to elevate the temperature of small ferrous tensile specimens prior to high strain-rate testing. A substantially uniform temperature of upto $600 \mathrm{C}$ was attained in less than a minute with no accompanying microstructural changes in the material. The same technique can be applied to non-ferrous metals by utilising conduction from a heated iron sleeve clamped around the specimen. When properly plotted against stress triaxiality parameter $\sigma_{m} / \sigma_{e}$, a general trend has been found for the ductility of specially-processed pure iron to decrease with start temperature over the range 


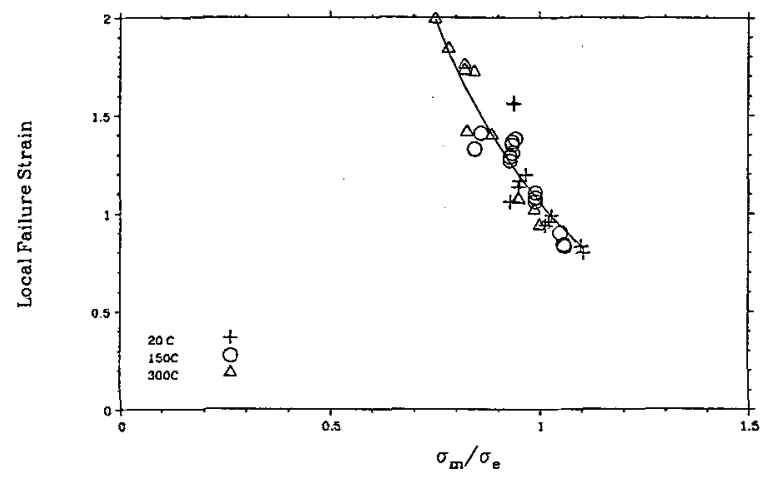

Figure 6: Local failure strain versus stress triaxiality factor for copper.

tested (20-400 C). An equation relating local fracture strain to the stress triaxiality, test start temperature and adiabatic temperature rise was derived from the experimental data and found to give good predictions of both fracture times and strains in numerical simulations of the experiment. For copper, no obvious correlation between fracture strain and temperature could be discerned from the experimental results. This suggests that the ductile fracture behaviour of the copper is largely temperature independent as well as strain-rate independent over the range tested to date $(20-300 \mathrm{C})$.

The effect of temperature on ductility at high strain-rates is difficult to quantify since account should be taken of the adiabatic temperature rise as well as the test start temperature. The former is strongly linked to the plastic strain at fracture which itself is primarily a function of stress triaxiality. Temperature rise, fracture strain and stress triaxiality are therefore inevitably closely linked. Tests such as described in this paper aim to decouple these effects and thereby enabled high strain-rate fracture to be studied in a more consistent and realistic manner.

\section{Acknowledgement}

This work was carried out under the UK Defence Research Agency Agreement Number CB/FRN/9/4/2062 $/ 155 /$ RARDE. The authors are grateful for this support and the help and advice of Mr. P. Church and his colleagues at Fort Halstead.

\section{References}

[1] I Davies and P Simpson. Induction Heating Handbook. McGraw-Hill Book Company, 1979.

[2] J W Hancock and A C MacKenzie. On the mechanisms of ductile failure in high strength steels subjected to multi-axial stress-state. Journal of Mechanics and Physics of Solids, 24:147-169, 1976.

[3] M S Mirza. Deformation and Fracture of Ductile Metals at High Strain Rates. PhD thesis, Department of Mechanical Engineering, University of Leeds, November 1993.

[4] T Shirakashi, K Maekawa, and E Usui. Flow stress of low carbon steel at high temperature and strain-rate. Bull. Jap. Soc. Proc. Engg, 17:161-166, 1983.

[5] C E Work and T J Dolan. The influence of strain rate and temperature on the strength and ductility of mild steel in torsion. Proc. ASTM, 53:611-626, 1953.

[6] F J Zerilli and R W Armstrong. Dislocation mechanics based constitutive relations for material dynamics calculations. Journal of Applied Physics, 61:1816-1825, 1987. 